\title{
Art in Flux at Event Two
}

\author{
Aphra Shemza \\ FLUX Events \\ Fountayne Road, \\ N15 London, UK \\ aphra@fluxevents.co.uk
}

\author{
Maria Almena \\ FLUX Events \\ 5 Fountayne Road, \\ N15 London, UK \\ maria@fluxevents.co.uk
}

\author{
Oliver Mag Gingrich \\ FLUX Events \\ 2, Oliver House, \\ W11 London, UK \\ oliver@fluxevents.co.uk
}

\section{INTRODUCTION}

Founded in 2016 at Light of Soho by the artists Maria Almena, Oliver Gingrich and Aphra Shemza, FLUX Events is a charitable organization committed to furthering the development of the media arts community in the UK. As an artist-led forum, FLUX was created out of a perceived necessity to bring artists together to discuss prevalent topics in the Media Arts in the UK.

FLUX offers a space for collaboration and exchange as key artists and organizations come together to profile their work. Through talks events, performance evenings, workshops, demonstrations and exhibitions, FLUX offers a space for contemplation, consideration and discussion, but also helps to bring these ideas to the wider public. FLUX provides a fluid platform to discuss strategies, processes and collective themes within the media arts.

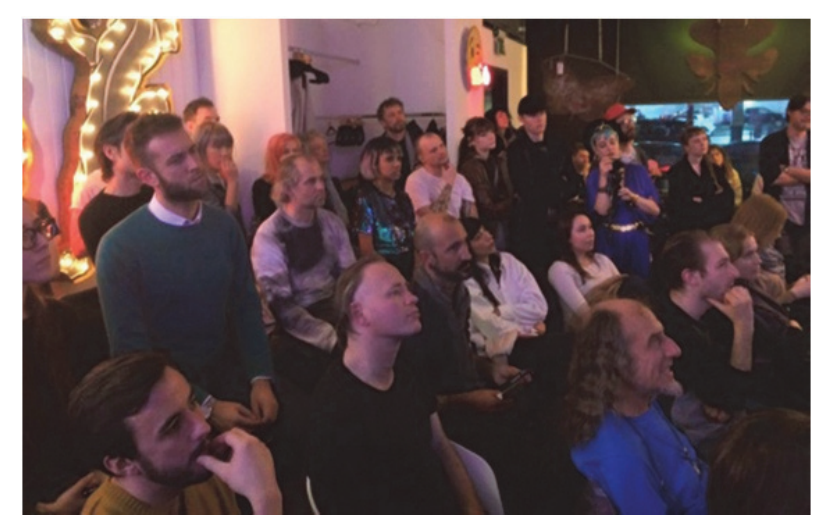

Figure 1: FLUX at Lights of Soho 2017.

\section{EVENT ONE}

Event One, the seminal exhibition that marked the beginnings of the Computer Arts Society (CAS) opened its doors in 1969. In the wake of the creative climate following Jasia Reichhardt's exhibition Cybernetic Serendipity, the three founders of CAS, George Mallen, Alan Sutcliffe and
John Lansdown decided to mark the beginnings of the UK's pre-eminent artist run organisation for computer-generated art. Presenting some of the most radical media artists of their time, Event One can be seen as a landmark exhibition for the media arts in the UK, assembling some of its most radical artists in a single space.

\section{EVENT TWO}

FLUX has been invited to take part in the Event Two exhibition at the Royal Academy in July 2019, in collaboration with EVA, the Computer Arts Society and the Lumen Prize. It is an important opportunity for FLUX to curate and provide a platform for contemporary media artists. Building on the legacy of Event One, an exhibition of the Computer Arts Society at the Royal Academy 50 years ago, the event will showcase some the original computational artworks from the Computer Art Society's collection as well as some of the very best cutting-edge talent globally. The FLUX cofounders, Maria Almena, Oliver Gingrich and Aphra Shemza embarked on the curation of the FLUX part of the exhibition, which will be centred around key themes in the Media Arts today.

\section{ART IN FLUX}

'Art in Flux' is FLUX event's annual exhibition, which brings most important concepts of today's media arts practice to the wider public. Over the last two years' these concepts have included topics such as Sustainability, Transcendence, Posthumanism, Light, Motion, and many others. Our program for 'Art in Flux' at Event Two highlights these key concepts, showcasing some of today's most radical media artists that challenge our conception of what this form consists of in 2019. While our key focus remains on London-based media artists, a mix of diverse practices from installation, to sculpture, from projection to performance will be at the forefront of our activity. 


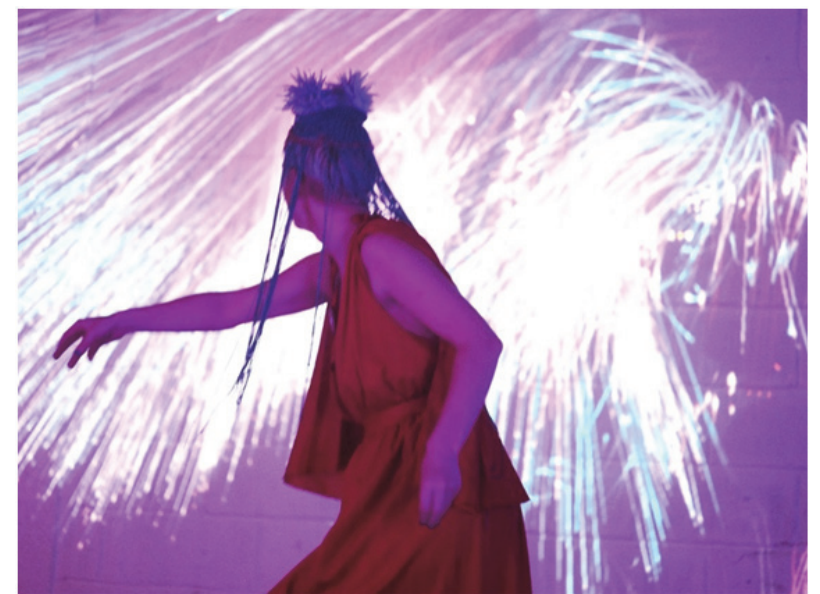

Figure 2: Maria Almena - Kimatica's Relax and Release. Image by http://www.sophielerouxdocu.com.

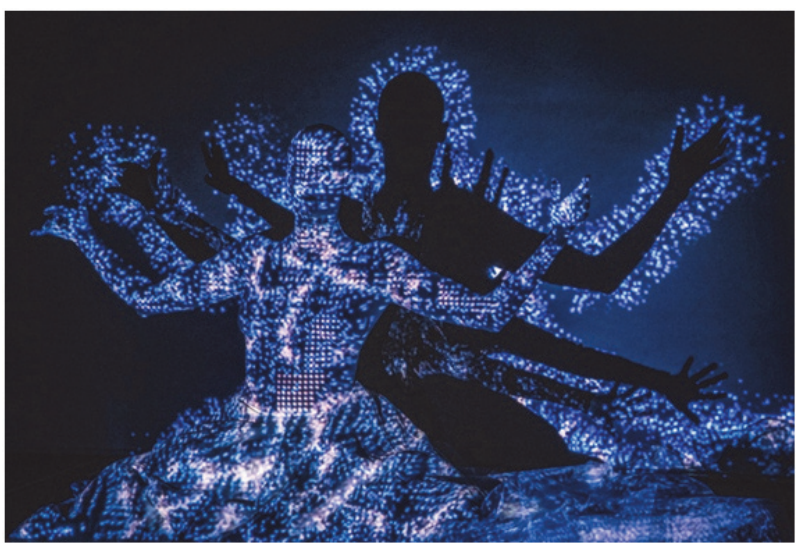

Figure 3: Kimatica's Transcendence Performance.

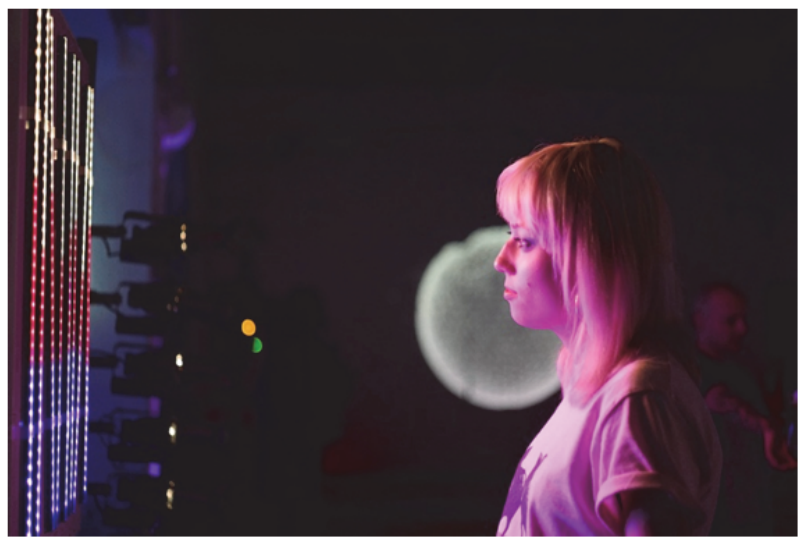

Figure 4: Audience with Aphra Shemza's work. Image by http://www.sophielerouxdocu.com.

\section{FLUX}

Discourse is at the core of FLUX's activities. At Event Two, we will be inviting the audience to a talk on pervasive data and $\mathrm{Al}$ - one of three curated FLUX talks this year. Furthermore, FLUX will invite selected artists participating in 'Art in Flux' at Event Two to profile their work at EVA London as part of a panel discussion on the exhibition and radical media practices in today's contemporary arts discourse in the UK. The panel at EVA London 2019 will be hosted by the three FLUX co-founders Aphra Shemza, Maria Almena and Oliver Gingrich.

\section{REFERENCES}

Mason, C. (2004) The Fortieth Anniversary of Event One at the Royal College of Art. EVA London 2009 Proceedings, pp.117-127. 